\title{
Commentary: Aortic valve sparing procedure: Is this the future of aortic root surgery?
}

Vito Domenico Bruno, MD, PhD, ${ }^{\mathrm{a}}$ and Mustafa Zakkar, PhD, FRCS(Ct-H) ${ }^{\mathrm{b}, \mathrm{c}}$

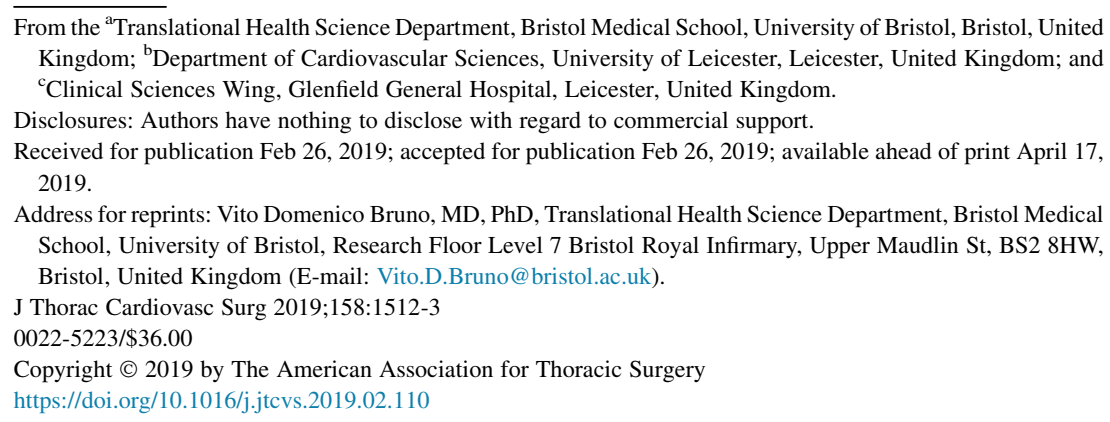

Since its introduction, the valve-sparing aortic root replacement (VSRR) procedure has been significantly refined $^{1}$ and it is now largely used particularly in specialized aortic surgery centers because it provides the important advantage of avoiding the use of a prosthetic valve. Despite the increasing use of the sparing techniques, the Bentall procedure remains a benchmark for aortic root replacement. But what is better? Answering this question is very difficult because patients with aortic root dilatation and aortic valve regurgitation (AR) represent a very heterogenous population: they differ in terms of age, presence of Marfan or other genetic syndromes, degree of AR, and aortic arch involvement. Therefore, every time we face this type of disease, tailoring the surgery to the specific patient is paramount. Kunihara and colleagues ${ }^{2}$ interrogated the Japan Cardiovascular Surgery Database to specifically compare VSRR with composite valve graft $(\mathrm{CVG})$. The study involves a very large population of elective patients undergoing aortic root replacement and provides the advantages of a propensity score matched analysis. From the results of the unmatched analysis it is evident that VSRR requires longer surgical times despite being less frequently associated with concomitant cardiac surgery procedures. These findings are representative of the higher technical requirements of the VSRR and its results might therefore be influenced by surgeon experience. There was an increasing number of sparing procedures over time. This might be the sign of growing confidence of the surgeons in performing this procedure regardless of its complexity as well as the recognition of the clinical advantages of this procedure compared with CVG. After matching, the authors found that despite prolonged operative times, VSRR had a better in-hospital survival rate compared with CVG and similar rates of postoperative morbidity, but VSRR was more frequently used in younger patients with fewer cardiovascular comorbidities. This is an important aspect that might have influenced the better

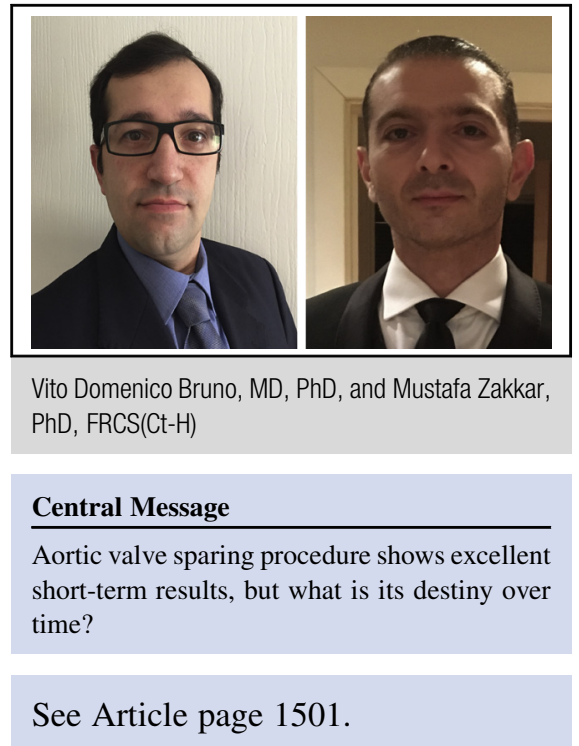

short-term clinical outcomes of these procedures. The regression model identified age $>65$ years as an independent factor for short-term mortality. The authors were unable to perfectly match the groups by age (standard mean difference, 0.154) and therefore they had younger patients in the VSRR group even after matching. This might have positively influenced the survival rates in this group. The authors attempted to reduce this bias by running an analysis after excluding the biological CVG, yet even in this subgroup analysis the VSRR had better outcomes. The results of the study clearly show that VSRR can be safely performed with very positive short-term survival rates and a low risk of complications. Unfortunately, the current study does not provide data on long-term results, especially in terms of recurrence of $\mathrm{AR}$ and, as recognized by the authors, this is the most important limitation. The shortterm results of VSRR are encouraging, but what is the fate of the aortic valve of these patients during the years after surgery? This study does not help us in responding this crucial question, but other authors have tried to answer it showing very promising results: Mastrobuoni and colleagues $^{3}$ recently reported a freedom for aortic valve reoperation of $89.6 \%$ at 10 years for the reimplantation technique, whereas David and colleagues ${ }^{4}$ reported an astonishing $96.2 \%$ freedom from moderate or severe AR at 15 to 20 years. With these very good results we should ask ourselves why we do not regularly spare the aortic 
valve. Someone could speculate that the more we perform VSRR, the better we become in doing it, and the better the long-term results will be. We do not agree with this simplistic view because several factors can influence the long-term valve-related outcomes and we still have to improve our understanding of the biodynamic characteristics of valve-sparing operations. Perhaps translational studies like that recently offered by Paulsen and colleagues $^{5}$ would help us in this difficult task, but there is no doubt that VSRR is becoming more popular and short-term results support its use. Surely, more long-term durability data are needed, but these very encouraging results are another step toward the future of aortic root surgery.

\section{References}

1. De Paulis R, Weltert L, Salica A, Weltert L, Chirichilli I. Biological solutions to aortic root replacement: valve-sparing versus bioprosthetic conduit. J Vis Surg. 2018;4:94

2. Kunihara T, Ichihara N, Miyata H, Motomura N, Sasaki K, Matsuhama M, et al Valve-sparing root replacement and composite valve graft replacement in patients with aortic regurgitation: from the Japan Cardiovascular Surgery Database. J Thorac Cardiovasc Surg. 2019;158:1501-11.e6.

3. Mastrobuoni S, de Kerchove L, Navarra E, Watremez C, Vancraeynest D, Rubay J, et al. Long-term experience with valve-sparing reimplantation technique for the treatment of aortic aneurysm and aortic regurgitation. J Thorac Cardiovasc Surg. 2019;158:14-23.

4. David TE, David CM, Feindel CM, Manlhiot C. Reimplantation of the aortic valve at 20 years. J Thorac Cardiovasc Surg. 2017;153:232-8.

5. Paulsen MJ, Kasinpila P, Imbrie-Moore AM, Wang H, Hironaka CE, Koyano TK et al. Modeling conduit choice for valve-sparing aortic root replacement on biomechanics with a 3-dimensional-printed heart simulator. J Thorac Cardiovasc Surg. 2019;158:392-403.

Access to The Journal of Thoracic and Cardiovascular Surgery Online is reserved for print subscribers!

Full-text access to The Journal of Thoracic and Cardiovascular Surgery Online is available for all print subscribers. To activate your individual online subscription, please visit The Journal of Thoracic and Cardiovascular Surgery Online, point your browser to http://www.mosby.com/jtcvs, follow the prompts to activate your online access, and follow the instructions. To activate your account, you will need your subscriber account number, which you can find on your mailing label (note: the number of digits in your subscriber account number varies from 6 to 10). See the example below in which the subscriber account number has been circled:

\section{Sample mailing label}

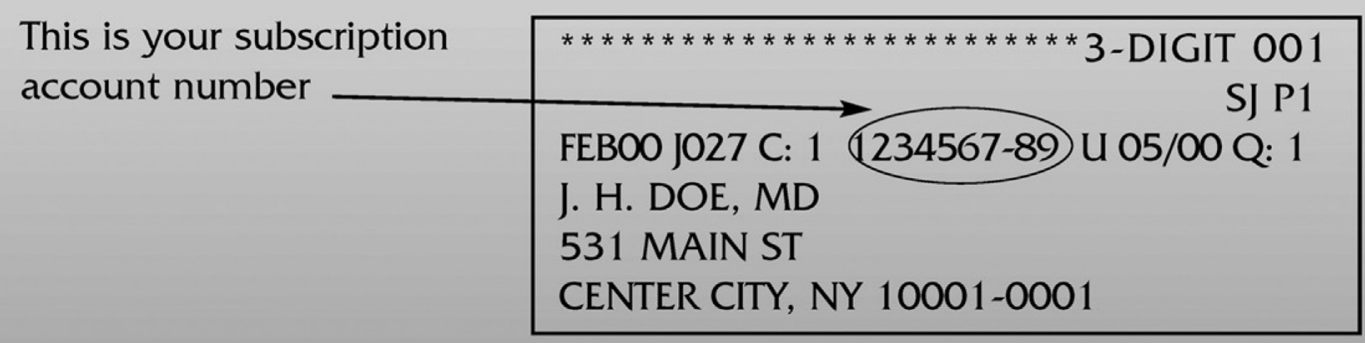

Personal subscriptions to The Journal of Thoracic and Cardiovascular Surgery Online are for individual use only and may not be transferred. Use of The Journal of Thoracic and Cardiovascular Surgery Online is subject to agreement to the terms and conditions as indicated online. 